\title{
SELEÇÃO DE LINHAGENS DE FEIJOEIRO COM TIPO DE GRÃO CARIOCA E COM OS ALELOS CO-4 E CO-5 DE RESISTÊNCIA À ANTRACNOSE
}

\author{
Selection of common bean strains with carioca grain type, and with the \\ alleles co-4 and co-5 for anthracnose resistance
}

\author{
Eduardo Henrique Keller Marcondes 1 , João Bosco dos Santos², Helton Santos Pereira ${ }^{3}$
}

\begin{abstract}
RESUMO
Objetivou-se, neste trabalho, identificar linhagens de feijão que reúnam, além da resistência à antracnose, alta produtividade de grãos do tipo carioca e resistência à mancha angular. Foram utilizadas 194 linhagens $\mathrm{F}_{5 \cdot 6}$ extraídas de sete famílias segregantes, selecionadas do cruzamento entre os genitores H147 e B1. A linhagem H147 possui grãos tipo carioca, portadora do alelo Co-5, que confere resistência a várias raças de Colletotrichum lindemuthianum. A linhagem B1 também possui grãos tipo carioca e é portadora do alelo Co-4, que confere resistência a outro grupo de raças do mesmo patógeno. As linhagens foram avaliadas na safra das águas 2005/2006, em Lavras, com a cultivar Talismã e H147 como testemunhas, com base na produtividade e tipo de grãos. Foram selecionadas 99 linhagens, as quais foram avaliadas na safra da seca/2006, juntamente com a testemunha Talismã, com base na produtividade, tipo de grão e resistência à mancha angular. Dessas 99 linhagens, foram selecionadas 24 , as quais foram avaliadas na safra de inverno/2006 em Lavras e Lambari, com base no tipo de grão e produtividade. Essas 24 linhagens foram inoculadas com a raça 321 de $C$. lindemuthianum, que quebra a resistência conferida pelo alelo $C o-4$, mas não o $C o-5$. Para verificar a presença do alelo $C o$ 4 foi utilizado um marcador SCAR que amplifica um fragmento de $950 \mathrm{pb}$ por meio do primer SAS 13 . Foi possível identificar 14 linhagens que possuem a pirâmide de alelos $\mathrm{Co}-4 / \mathrm{Co}-5$ e entre elas, quatro destacaram-se em todos os caracteres avaliados.
\end{abstract}

Termos para indexação: Phaseolus vulgaris, resistência, seleção, Colletotrichum lindemuthianum.

\begin{abstract}
The objective of the research was to identify bean strains that possess at the same time resistance to anthracnose, high grain yield of Carioca grain type and resistance to angular leaf spot. 194 strains $\mathrm{F}_{5: 6}$ were taken from seven segregating families derived from the cross H147 x B1. The H147 line has Carioca grain type and Co-5 resistance allele to several races of C. lindemuthianum. The B1 line also has the Carioca grain type, and the $\mathrm{Co}-4$ resistance allele against others races of the same pathogen. The strains were evaluated in the spring/summer (2005/2006) in the municipality of Lavras, in the Southern of the State of Minas Gerais, with the Talismã cultivar and H147 line as check, based mainly on grain type and grain yield. 99 strains, together with the Talismã check, were selected and evaluated based on grain yield, grain type and angular leaf spot resistance in the summer (2006) in the same place. From these 99 strains, 24 strains were selected and evaluated in the winter/spring (2006) in two places, Lavras and Lambari, based on the type of grain and productivity, and using the same check. Those 24 strains were also inoculated with the race 321 of $C$. lindemuthianum that break the resistance of the $\mathrm{Co}-4$ allele, but not of the $\mathrm{Co}-5$. The SCAR marker using the SAS13 primer was used to detect the presence of the $\mathrm{Co}-4$ allele. Fourteen strains were identified that have the $\mathrm{Co}-4 / \mathrm{Co}-5$ allele pyramid, and, among them, four stand out in all evaluated features.
\end{abstract}

Index terms: Phaseolus vulgaris, resistance, selection, Colletotrichum lindemuthianum.

(Recebido em 24 de janeiro de 2008 e aprovado em 11 de agosto de 2009)

\section{INTRODUÇÃO}

Apesar de o Brasil ser o maior produtor e consumidor de feijão (Phaseolus vulgaris L.), a produtividade nacional ainda é considerada baixa, porque a cultura é afetada por várias doenças. Entre elas, destacase a antracnose causada pelo fungo Colletotrichum lindemuthianum (Sacc. \& Magnus) Scrib. Esse patógeno possui alta variabilidade patogênica na maioria das regiões produtoras, tendo as raças 65,81 e 73 observadas com maior frequência nos levantamentos realizados nos últimos dez anos (Silva, 2004).

Uma medida recomendada para o controle desse patógeno é a obtenção de cultivares resistentes. No entanto, cultivares com um único alelo de resistência, em geral, são protegidas da doença por pouco tempo, devido à grande variabilidade do patógeno. A piramidação, que é a inserção de vários alelos de resistência em um único genótipo, é uma estratégia que pode aumentar a vida útil das cultivares resistentes (Young \& Kelly, 1997). No

\footnotetext{
${ }^{1}$ Cascavel, PR

2Univercidade Federal de Lavras/UFLA - Departamento de Biologia/DBI - Lavras, MG - jbsantos@dbi.ufla.br

${ }^{3}$ Embrapa Arroz e Feijão - Santo Antonio de Goiás, GO
} 
entanto, um problema associado com a construção de uma pirâmide de genes é a dificuldade em avaliar a presença dos alelos de resistência em um único genótipo por meio de inoculações (Fehr, 1987; Michelmore, 1995). Uma alternativa viável é a utilização de marcadores moleculares associados a inoculações (Alzate-Marin et al., 1999).

Dentre os alelos de resistência, o Co-4 e o Co-5 estão entre os mais importantes, pois conferem proteção contra a maioria das raças presentes nas principais regiões produtoras (Ishikawa et al., 2005). Dessa forma, uma pirâmide de alelos $\mathrm{Co}-4 / \mathrm{Co}-5$ é altamente desejável, pois a cultivar obterá resistência a praticamente todas as raças do patógeno, nas principais regiões produtoras.

Na obtenção de cultivares de feijão com resistência à antracnose, outros atributos agronômicos também devem ser considerados para atender à preferência do consumidor e produtor. Entre eles, o tipo de grão semelhante ao da cultivar Carioca, alta produtividade de grãos e também a resistência à mancha angular, que é uma doença importante na maioria das regiões produtoras, principalmente na safra da seca.

Objetivou-se, no presente trabalho, selecionar linhagens de feijão que reunissem, além da pirâmide de alelos de resistência à antracnose, alta produtividade, grãos tipo carioca e resistência à mancha angular.

\section{MATERIAL E MÉTODOS}

Foram utilizadas 194 linhagens $\mathrm{F}_{5 \cdot 6}$, extraídas de sete famílias segregantes, selecionadas do cruzamento entre os genitores H147 e B1 Parrella et al. (2008). A linhagem H147 possui grãos tipo carioca e é portadora do alelo $C o$ 5 , que confere resistência a várias raças de $C$. lindemuthianum. A linhagem B1 também possui grãos tipo carioca e é portadora do alelo $\mathrm{Co}-4$, que confere resistência a outro grupo de raças do mesmo patógeno. As linhagens foram avaliadas na área experimental do Departamento de Biologia da Universidade Federal de Lavras - UFLA e na estação experimental Nova Baden da Empresa de Pesquisa Agropecuária de Minas Gerais (Epamig), em Lambari, MG.

Na safra das águas de 2005/2006, as 194 linhagens foram avaliadas juntamente com duas testemunhas (H147 e Talismã), no município de Lavras, MG. Foram semeadas 15 sementes por metro linear, em parcela de uma linha de um metro, espaçada de $0,50 \mathrm{~m}$. Utilizou-se o delineamento látice 14 x 14, com duas repetições. Foram avaliadas e selecionadas as linhagens mais promissoras quanto ao tipo e à produtividade de grãos.

$\mathrm{Na}$ safra da seca de 2006, foram avaliadas 99 linhagens selecionadas da safra anterior. O experimento foi conduzido no Departamento de Biologia da UFLA e utilizado o delineamento látice 10 x 10, com três repetições, com parcela constituída de duas linhas de dois metros. Foi utilizada como testemunha, a cultivar Talismã. As características avaliadas foram produtividade, tipo de grão e reação à mancha angular.

A partir desses resultados, foram selecionadas 24 linhagens que foram avaliadas no Departamento de Biologia da UFLA e na fazenda experimental da Epamig, na safra do inverno de 2006. Foi utilizado o delineamento látice $5 \times 5$, com três repetições, sendo a parcela constituída de duas linhas de $3 \mathrm{~m}$, com a cultivar Talismã como testemunha.

Foi avaliado o tipo de grãos por meio da escala descritiva de notas variando de 1 (grãos tipo carioca) a 5 (grãos fora do padrão carioca), segundo Marques Júnior (1997). O padrão tipo carioca corresponde a grãos com coloração creme-clara, estrias marrom-claras, sem halo, peso médio dos grãos $(0,23 \mathrm{~g}$ a $0,25 \mathrm{~g})$ e não achatado.

A produção de grãos foi medida em g/parcela e, posteriormente, foi realizada a transformação dos dados em kg/ha para padronização, devido aos diferentes tamanhos de parcelas.

A avaliação de severidade de mancha angular foi realizada utilizando-se uma chave descritiva de notas proposta por Schoonhoven \& Pastor-Corrales (1987) em que $1=0 \%$ de doença; $3=5 \%-10 \%$ de doença; $5=20 \%$ de doença; $7=60 \%$ de doença e $9=90 \%$ de doença, sendo o genótipo com nota maior ou igual a três, suscetível e menor do que três, resistente.

Para verificar-se a presença do alelo Co-5 de resistência à antracnose nas 24 linhagens, foi realizada a inoculação com uma suspensão de conídios da raça 321, proveniente de cultura monospórica, na concentração de $1,2 \times 10^{6}$ conídios/ml, a qual foi pulverizada nas linhagens, 10 dias após a semeadura, de acordo com procedimento usado por Parrella et al. (2008).

A presença do alelo $\mathrm{Co}-4$ de resistência à antracnose nas linhagens foi detectada por meio do marcador SCAR, amplificado pelo primer SAS 13 identificado por Young et al. (1998), que se encontra a $0,39 \mathrm{cM}$ do alelo $C o-4^{2}$ e também do alelo Co-4 (Awale \& Kelly, 2001). O DNA foi extraído das 24 linhagens selecionadas, utilizando o procedimento empregado por Parrella et al. (2008) a partir de cerca de 2,0g de folhas jovens, amostradas em 10-12 plantas de cada linhagem, e as reações foram realizadas em um termociclador Eppendorf MasterCycler Gradient 5331. Os fragmentos gerados pelas reações foram separados em gel de agarose $1 \%$.

As características avaliadas nos experimentos de campo foram submetidas à análise individual e conjunta de variância. $\mathrm{O}$ efeito de tratamento foi considerado como 
aleatório nos látices 14 x 14 e 10 x 10 e como fixo no 5 x 5 . Para as análises conjuntas por ambientes, foram utilizadas as médias ajustadas dos tratamentos comuns (Pimentel Gomes, 1976). As médias das 24 linhagens selecionadas foram agrupadas, por meio do teste de Scott \& Knot (1974).

Com o resultado das análises individuais para produção, tipo de grãos e mancha angular nos látices $14 \mathrm{x}$ 14 e $10 \times 10$, foi estimada a herdabilidade $\left(h^{2}\right)$ e seus respectivos limites inferior e superior $(\mathrm{P}=0,05)$, de acordo com Knapp et al. (1985). O ganho com a seleção foi estimado por meio da expressão GS $=\left(\mathrm{ds} \times \mathrm{h}^{2}\right) \times 100$, em que ds é o diferencial de seleção.

\section{RESULTADOS E DISCUSSAO}

As análises individuais para a produção de grãos nas safras das águas 2005/2006, seca/2006, inverno/2006 em Lavras e inverno/2006, em Lambari são apresentadas na Tabela 1. Pode ser observada a existência de diferença significativa entre as linhagens para o caráter, a $1 \%$ de probabilidade, para as safras das águas e seca, ambas em Lavras e na safra de inverno em Lambari. Na safra de inverno em Lavras, houve diferença significativa a 5\%.

Para a produção de grãos, o látice foi eficiente, na safra das águas 2005/2006, em 20,04\%, quando comparado com o delineamento em blocos completos e $4,49 \%$, na safra da seca/2006. Resultados similares foram obtidos por Marques Júnior (1997).

A média na safra de inverno/2006, em Lavras, apresentou-se superior às demais devido às condições experimentais superiores. Em contrapartida, no experimento conduzido em Lambari, a média obtida foi a menor entre as quatro safras. Isso ocorreu, provavelmente, devido a problemas de manejo do experimento, o que é evidenciado na menor precisão experimental, medida pelo coeficiente de variação (CV). Na safra das águas 2005/2006, o (CV) também indica baixa precisão experimental, que se deveu ao tamanho de parcela utilizado $\left(0,5 \mathrm{~m}^{2}\right)$. Bertolucci et al. (1991) demonstraram que é viável o uso de pequenas parcelas na avaliação de linhagens, mesmo tendo uma estimativa de CV maior. Apesar de algumas estimativas de $\mathrm{CV}$ serem altas, observou-se diferença genética entre as linhagens em todos os experimentos.

As estimativas de herdabilidade da produção na avaliação das águas 2005/2006 e seca/2006 (Tabela 1) indicam que pode haver sucesso com a seleção, pois todas elas estão dentro do intervalo de confiança que foi sempre positivo (Ramalho et al., 1993).

Em todos os experimentos foi utilizada a cultivar Talismã como testemunha, tendo a sua produtividade média sida superior em todos os experimentos, quando comparada com a média geral. Entretanto, na safra de inverno, 16,67\% das linhagens apresentaram produção superior.

Para as análises individuais de tipo de grão (nota) nas safras das águas 2005/2006, seca/2006 e inverno/2006 (Tabela 1), houve diferença significativa entre as linhagens (P£0,01). A precisão experimental medida pelo coeficiente de variação foi semelhante às obtida por Pereira et al. (2004), Silva et al. (2006) e Parrella et al. (2008), sendo eficiente na

Tabela 1 - Resumo das análises de variância individuais da produção de grãos (kg/ha), tipo de grão e mancha angular, avaliadas nas safras das águas 2005/2006, seca/2006, inverno (Inv.) de 2006, em Lavras e inverno/2006, em Lambari, juntamente com as estimativas de herdabilidade e respectivos limites inferior (LI) e superior (LS).

\begin{tabular}{|c|c|c|c|c|c|c|c|c|}
\hline \multirow[t]{2}{*}{ Caráter } & \multicolumn{4}{|c|}{ Produção de grãos } & \multicolumn{3}{|c|}{ Tipo de grãos ${ }^{1}$} & \multirow{2}{*}{$\begin{array}{c}\begin{array}{c}\text { Mancha } \\
\text { angular }^{2}\end{array} \\
\begin{array}{c}\text { Seca/ } \\
\text { Lavras }\end{array} \\
\end{array}$} \\
\hline & $\begin{array}{l}\text { Águas/ } \\
\text { Lavras }\end{array}$ & $\begin{array}{c}\text { Seca/ } \\
\text { Lavras }\end{array}$ & $\begin{array}{c}\text { Inv./ } \\
\text { Lavras }\end{array}$ & $\begin{array}{l}\text { Inv./ } \\
\text { Lamb. }\end{array}$ & $\begin{array}{l}\text { Águas/ } \\
\text { Lavras }\end{array}$ & $\begin{array}{c}\text { Seca/ } \\
\text { Lavras }\end{array}$ & $\begin{array}{c}\text { Inv./ } \\
\text { Lavras }\end{array}$ & \\
\hline $\mathrm{N}^{\mathrm{o}}$ linhagens & 196 & 100 & 25 & 25 & 196 & 100 & 25 & 100 \\
\hline QM linhagens & $* *$ & $* *$ & $*$ & $* *$ & $* *$ & $* *$ & $* *$ & $* *$ \\
\hline Média & 1496 & 2088 & 3007 & 1239 & 2,53 & 2,56 & 2,16 & 4,34 \\
\hline Média test. & 1900 & 2117 & 3652 & 1242 & 2,25 & 3,00 & 2,66 & 5,66 \\
\hline $\mathrm{CV}(\%)$ & 37,42 & 18,20 & 14,11 & 24,98 & 10,43 & 11,00 & 14,02 & 22,43 \\
\hline $\mathrm{h}^{2}(\%)$ & 58,00 & 42,44 & - & - & 48,90 & 50,31 & - & 67,55 \\
\hline $\mathrm{h}_{\mathrm{LI}}^{2}$ & 43,63 & 18,98 & - & - & 31,55 & 29,86 & - & 54,23 \\
\hline $\mathrm{h}_{\mathrm{LS}}^{2}$ & 68,58 & 59,90 & - & - & 61,84 & 65,29 & - & 77,35 \\
\hline
\end{tabular}

* e ** Significativo, respectivamente, a $5 \%$ e $1 \%$ de probabilidade, pelo teste $\mathrm{F} ;{ }^{1} 1=$ grãos tipo carioca a $5=$ grãos fora do padrão carioca; ${ }^{2} 1=0 \%$ de doença a $9=90 \%$ de doença. 
detecção de heterogeneidade das linhagens. Pode-se observar também que houve uma redução nas médias das linhagens, como consequência da seleção realizada, relativamente à média da testemunha. Vale ressaltar que esse caráter foi um dos principais avaliados em todas as gerações. Outro fato interessante é que o tipo de grãos da testemunha foi inferior à média das linhagens nas safras da seca e inverno em Lavras, indicando, assim, que seus grãos estão em conformidade com o padrão carioca. Consequentemente, infere-se que há linhagens superiores à testemunha, como verificado por Pereira et al. (2004) e Parrella et al. (2008).

As estimativas de herdabilidade foram médias e os limites inferiores foram positivos, indicando haver chances de ganho com a seleção, um resultado similar ao da produtividade de grãos. Entretanto, os menores valores de CV podem garantir maior sucesso com a seleção.

A reação à mancha angular foi avaliada apenas na safra da seca/2006. Essa época foi escolhida por ser a ideal para a ocorrência da doença em campo, pois o fungo encontra condições favoráveis com temperaturas moderadas, períodos suficientemente longos de alta umidade e ação de ventos (Sartorato et al., 1996). Observase que houve diferença genética entre as linhagens $(\mathrm{P}=0,01)$ e a eficiência do látice foi de apenas $3,7 \%$ superior ao delineamento blocos casualizados (Tabela 1). Essa baixa eficiência do látice é um bom indicativo, e indica que a distribuição do inóculo no campo foi uniforme.

A estimativa de herdabilidade foi alta para o caráter, estando de acordo com os resultados obtidos por Pereira et al. (2004), Couto et al. (2005) e Silva et al. (2006) e sugere sucesso com a seleção das famílias mais resistentes, apesar do CV ter sido ligeiramente superior aos obtidos por esses autores.

Quando foram comparadas as médias das linhagens e a da testemunha, observou-se que as linhagens tiveram um desempenho ligeiramente superior, o que demonstra que existem linhagens com maior nível de resistência. Esse resultado foi semelhante ao obtido por Silva et al. (2006) e fica demonstrada a suscetibilidade da cultivar Talismã à mancha angular. Uma possível causa da resistência de algumas linhagens, é a presença de um alelo dominante de resistência, proveniente do genitor $\mathrm{H} 147$, derivado da linhagem ESAL 696 (Pereira et al., 2004).

Para estimar o ganho com a seleção e a correlação entre os caracteres, foram utilizados os dados obtidos na safra da seca/2006, na qual utilizaram-se 100 linhagens.

Considerando-se a seleção das quatro melhores linhagens para tipo de grão, produtividade e mancha angular, separadamente (seleção direta), observaram-se ganhos elevados para todos os caracteres (Tabela 2), semelhantes aos obtidos por Pereira et al. (2004), Couto et al. (2005), Couto et al. (2008), Silva et al. (2006) e Parrella et al. (2008). Quando foram considerados todos os caracteres em conjunto, foi adotado como critério os melhores valores primeiramente para tipo de grãos, seguido de reação à mancha angular e, por último, produtividade. Com esse procedimento destacaram-se as linhagens 70, 71, 126 e 171. Esse critério foi adotado pois, nas fases iniciais de avaliação, maior atenção deve ser dada a caracteres com maior herdabilidade (Ramalho et al., 1993). Observaram-se ganhos com o tipo de grão e resistência à mancha angular, porém houve ligeira redução da produtividade. Ganhos com a produtividade podem ser mais eficientemente estimados quando se utilizam experimentos em vários locais e em gerações mais avançadas, devido ao fato de esse caráter ser muito influenciado pelo ambiente. Dessa forma, a interação genótipos $\mathrm{x}$ ambientes pode ser melhor estimada, dando maior confiabilidade aos resultados (Ramalho et al., 1993).

A seleção baseada em um único caráter (seleção direta), como a utilizada para estimar o ganho com a seleção no primeiro caso, tem se mostrado inadequada, pois conduz a um produto final superior apenas quanto ao caráter considerado e um desempenho desfavorável para os outros caracteres. Assim, a seleção simultânea, como a realizada no segundo caso, mostra-se mais eficiente, por aumentar a chance de êxito em um programa de melhoramento (Cruz \& Carneiro, 2003). Porém, nota-se que há uma redução nos ganhos com a seleção, fato também

Tabela 2 - Estimativas de ganho esperado com a seleção das quatro linhagens de maior expressão para produção (kg/ ha), tipo de grãos e reação à mancha angular.

\begin{tabular}{cccc}
\hline Estimativa & Produção & Tipo de grãos & Reação à mancha angular $^{3}$ \\
\hline GS $^{1}$ & $221,70(10,62 \%)$ & $-0,22(8,60 \%)$ & $-1,23(28,34 \%)$ \\
GS $^{2}$ & $-75,89(-3,63 \%)$ & $-0,20(7,81 \%)$ & $-0,47(10,83 \%)$ \\
\hline
\end{tabular}

${ }^{1}$ Ganho com a seleção de 4 em 100 linhagens (4\%), baseada em cada caráter; ${ }^{2}$ Ganho com a seleção de 4 em 100 linhagens (4\%), considerando todas as características em conjunto; ${ }^{3} 1=$ grãos tipo carioca a $5=$ grãos fora do padrão carioca; $;{ }^{4} 1=0 \%$ de doença a $9=90 \%$ de doença. 
constatado por Pereira et al. (2004), Couto et al. (2005), Silva et al. (2006) e Parrella et al. (2008). Isso pode ser devido a uma correlação desfavorável entre os caracteres avaliados. Entretanto, não se observou nenhuma correlação entre eles, indicando assim a possibilidade de seleção de linhagens que sejam superiores em todos os caracteres avaliados.

$\mathrm{Na}$ Tabela 3, estão representadas as análises conjuntas para produção e tipo de grão das 24 linhagens superiores. Para a produção de grãos, as fontes de variação safras e interação, safras x linhagens foram significativas a $1 \%$ de probabilidade e a fonte linhagens a $5 \%$. Nota-se que a média das linhagens é inferior à média da testemunha (Talismã). Isso ocorreu, provavelmente, porque o genitor B1 possui baixo potencial produtivo, embora tenha um tipo de grão semelhante ao Carioca, além de ser portador do alelo de resistência à antracnose $\mathrm{Co}-4$. Entretanto, a diferença entre as linhagens indica a possibilidade de seleção de algumas superiores, em produtividade de grãos. Já para tipo de grãos, as diferenças entre as linhagens foram mais acentuadas e, como esperado, não ocorreu interação devido à menor sensibilidade do caráter ao ambiente.

Para a identificação do alelo $C o-5$, as 24 linhagens foram inoculadas com a raça 321, que é compatível com genótipos de feijoeiro que possuam o alelo $\mathrm{Co}-4$. O resultado obtido com essa inoculação foi a relação de 14 resistentes : 3 segregantes : 7 suscetíveis, ou seja 14 linhagens possuem o alelo $C o-5$ de resistência à antracnose.

$\mathrm{O}$ alelo $\mathrm{Co}-4$, foi identificado em todas as 24 linhagens (Figura 1). Vale salientar que as famílias de onde foram selecionadas as linhagens já haviam sido previamente selecionadas como portadoras do alelo $\mathrm{Co}-4$, por meio do marcador SAS 13 (Parrella et al., 2008). Como esse marcador está localizado a $0,39 \mathrm{cM}$ do loco $\mathrm{Co}-4$, o resultado obtido é confiável (Young et al., 1998). Com isso, foi possível identificar 14 linhagens que possuem a pirâmide de alelos $\mathrm{Co}-4 / \mathrm{Co}-5$.

Considerando a produtividade, tipo de grãos e a presença da pirâmide de alelos $\mathrm{Co}-4 / \mathrm{Co}-5$, destacaram-se as linhagens 1, 71, 126 e 169 (Tabela 4). Comparando-se essas linhagens superiores com base na média das avaliações, com as quatro que seriam selecionadas (70, 71, 126 e 171) apenas na safra anterior (seca/2006), duas são comuns (71 e 126). Isso mostra a eficiência parcial em se realizar a seleção com as características avaliadas em conjunto e com base em um único experimento. Apenas a linhagem 70 exibiu menor produtividade, porém, não se deve esquecer que esse caráter é muito influenciado pelo ambiente e que a seleção foi baseada apenas em uma única avaliação. A eliminação da linhagem 171 que seria

Tabela 3 - Resumo das análises de variância conjuntas para produção e tipo de grãos.

\begin{tabular}{|c|c|c|c|c|}
\hline \multirow{2}{*}{ Fontes de Variação } & \multicolumn{3}{|c|}{ Produção (kg/ha) } & \multirow{2}{*}{$\begin{array}{c}\text { Tipo de grãos } \\
\text { QM }\end{array}$} \\
\hline & GL & QM & GL & \\
\hline Safras (S) & 3 & $37849584,3^{* *}$ & 2 & $0,6192 * *$ \\
\hline Linhagens (L) & 24 & $346294,556 *$ & 24 & $0,1677 * *$ \\
\hline SXL & 72 & $352506,4 * *$ & 48 & $0,0744^{\mathrm{ns}}$ \\
\hline Erro médio & 436 & 208746,9 & 388 & 0,077 \\
\hline Média & - & 1980,71 & - & 2,27 \\
\hline Média da testemunha & - & 2256,25 & - & 2,64 \\
\hline $\mathrm{CV}(\%)$ & - & 18,34 & - & 7,7 \\
\hline
\end{tabular}

* e ${ }^{* *}$ Significativo, a 5\% e $1 \%$ de probabilidade, pelo teste $\mathrm{F} ;{ }^{\text {ns }}-$ não significativo, pelo teste $\mathrm{F} ;{ }^{1} 1$ = grãos tipo carioca a $5=$ grãos fora do padrão carioca.

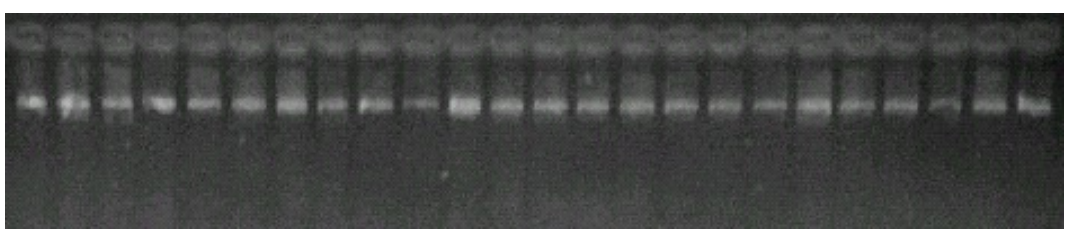

Figura 1 - Banda de 950pb, amplificada pelo marcador SAS13, nas 24 linhagens selecionadas. 
Tabela 4 - Médias ajustadas de produção, tipo de grão, reação à mancha angular e alelos de resistência presentes nas linhagens.

\begin{tabular}{|c|c|c|c|c|c|c|}
\hline Linha-gens & Produção & a) $)^{1}$ & Tipo & & Reação à mancha angular ${ }^{4}$ & Alelos de resistência \\
\hline 1 & 2165,50 & a & 2,00 & $\mathrm{~b}$ & 5,70 a & Co- 4, Co-5 \\
\hline 7 & 2142,50 & $\mathrm{a}$ & 2,30 & $\mathrm{a}$ & $4,10 \mathrm{~b}$ & Co- 4, Co- 5 \\
\hline 28 & 2224,00 & a & 2,22 & $b$ & 6,80 a & Co- 4, Co- 5 \\
\hline 41 & 1990,00 & a & 2,19 & $\mathrm{~b}$ & 6,31 a & Co- 4, Co- 5 \\
\hline 49 & 1116,25 & $\mathrm{c}$ & 2,39 & a & $3,30 \mathrm{~b}$ & Co-4 \\
\hline 70 & 1632,00 & $\mathrm{~b}$ & 2,23 & $\mathrm{~b}$ & $2,38 \mathrm{~b}$ & Co-4 \\
\hline 71 & 2058,50 & a & 1,93 & $\mathrm{~b}$ & $3,69 \mathrm{~b}$ & Co-4, Co-5 \\
\hline 79 & 1797,50 & $\mathrm{~b}$ & 2,35 & a & $4,44 \quad b$ & $\mathrm{Co}-4$ \\
\hline 83 & 1696,50 & $\mathrm{~b}$ & 2,19 & $\mathrm{~b}$ & $4,00 \mathrm{~b}$ & Co-4 \\
\hline 96 & 1756,50 & $\mathrm{~b}$ & 2,30 & $\mathrm{a}$ & $3,65 \mathrm{~b}$ & Co-4 \\
\hline 159 & 2070,50 & $\mathrm{a}$ & 2,34 & $\mathrm{a}$ & $4,12 b$ & $\mathrm{Co}-4, \mathrm{Co}-5$ \\
\hline 104 & 1884,75 & $\mathrm{~b}$ & 2,27 & $\mathrm{a}$ & $3,45 \quad b$ & $\mathrm{Co}-4$ \\
\hline 107 & 2275,00 & $\mathrm{a}$ & 2,16 & b & $3,73 \mathrm{~b}$ & Co-4 \\
\hline 115 & 2321,00 & $\mathrm{a}$ & 2,39 & $\mathrm{a}$ & 5,12 a & Co- 4, Co-5 \\
\hline 123 & 1902,50 & $\mathrm{~b}$ & 2,46 & $\mathrm{a}$ & $4,52 \mathrm{~b}$ & Co- 4, Co- 5 \\
\hline 125 & 1574,50 & $\mathrm{~b}$ & 2,35 & $\mathrm{a}$ & $3,46 \quad b$ & $\mathrm{Co}-4, \mathrm{Co}-5 ?$ \\
\hline 126 & 2038,50 & $\mathrm{a}$ & 2,07 & $\mathrm{~b}$ & $4,15 \mathrm{~b}$ & $\mathrm{Co}-4, \mathrm{Co}-5$ \\
\hline 141 & 2017,25 & $\mathrm{a}$ & 2,32 & $\mathrm{a}$ & 5,29 a & $\mathrm{Co}-4, \mathrm{Co}-5$ \\
\hline 160 & 1825,25 & $\mathrm{~b}$ & 2,40 & $\mathrm{a}$ & 5,63 a & $\mathrm{Co}-4, \mathrm{Co}-5 ?$ \\
\hline 167 & 2020,00 & $\mathrm{a}$ & 2,24 & $\mathrm{~b}$ & $4,23 \quad b$ & $\mathrm{Co}-4, \mathrm{Co}-5$ \\
\hline 168 & 1767,25 & $\mathrm{~b}$ & 2,18 & b & $3,58 \mathrm{~b}$ & $\mathrm{Co}-4, \mathrm{Co}-5 ?$ \\
\hline 169 & 2332,00 & $\mathrm{a}$ & 2,19 & b & $4,69 \mathrm{~b}$ & Co- 4, Co-5 \\
\hline 171 & 2408,00 & $\mathrm{a}$ & 2,29 & $\mathrm{a}$ & $4,38 \quad b$ & Co- 4, Co-5 \\
\hline 180 & 2247,00 & $\mathrm{a}$ & 2,29 & $\mathrm{a}$ & $4,51 \quad b$ & Co- 4, Co-5 \\
\hline Talismã & 2256,00 & $\mathrm{a}$ & 2,64 & $\mathrm{a}$ & 5,63 a & - \\
\hline
\end{tabular}

Médias seguidas da mesma letra são do mesmo grupo, pelo teste de Scott-Knot $\left({ }^{1}=5 \% \mathrm{e}^{2}=10 \%\right)$; ? indica a possibilidade de as linhagens terem ou não o alelo de resistência $C o-5 ;{ }^{3} 1=$ grãos tipo carioca a $5=$ grãos fora do padrão carioca. ${ }^{4} 1=0 \%$ de doença a $9=90 \%$ de doença.

selecionada na seca de 2006 deveu-se principalmente ao seu pior tipo de grão. Assim, a intensidade de seleção moderada praticada nessa safra foi benéfica para garantir a seleção de linhagens superiores após múltiplas avaliações.

Com relação à mancha angular, nota-se que as duas seleções realizadas tanto na média das avaliações $(4,55)$ quanto na média da safra da seca/2006 $(3,65)$, tiveram notas médias inferiores à da testemunha $(5,63)$ e demonstra a eficiência na seleção. O aumento da suscetibilidade média à mancha angular $(4,55)$, com a seleção realizada na média das avaliações, foi devido à inclusão da linhagem 1, que se mostrou suscetível, porém, ela apresenta produtividade comparável com a Talismã e a segunda melhor nota para tipo de grão, além da pirâmide de alelos $\mathrm{Co}-4 / \mathrm{Co}-5$.

\section{CONCLUSÕES}

Foi possível identificar 14 linhagens que possuem a pirâmide de alelos $\mathrm{Co}-4 / \mathrm{Co}$-5. Entre elas, quatro linhagens destacaram-se também por apresentarem grãos tipo carioca aceitáveis pelo consumidor, alta produtividade de grãos e três delas com alto nível de resistência à mancha angular.

\section{AGRADECIMENTOS}

À FAPEMIG, pelo apoio financeiro e ao CNPq, pela bolsa de Mestrado para o primeiro autor. 


\section{REFERÊNCIAS BIBLIOGRÁFICAS}

ALZATE-MARIN, A.L.; MENARIM, H.; CARVALHO, G.A.; BARROS, E.G.; MOREIRA, M.A. Improved Selection with Newly Identified RAPD Markers Linked to Resistance Gene to Four Pathotypes of Colletotrichum lindemuthianum in Common Bean. Phytopathology, Saint Paul, v.89, n.4, p.281-285, Apr. 1999.

AWALE, H.E.; KELLY, J.D. Development of SCAR markers linked to Co- $4^{2}$ gene in common bean. Annual Report of Bean Improvement Cooperative, Fort Collins, v.44, p.119-120, 2001.

BERTOLUCCI, F.L.G.; RAMALHO, M.A.P.; DUARTE, G.S. Alternativas de tamanho e forma da parcela para avaliação de progênies de feijoeiro (Phaseolus vulgaris L.). Ciência e Prática, Lavras, v.15, n.3, p.295-305, jul./ set. 1991.

COUTO, M.A.; SANTOS, J.B.; ABREU, A.F.B. Selection of carioca type common bean strains resistant to anthracnose and to angular leaf spot. Crop Breeding and Applied Biotechnology, Londrina, v.5, n.3, p.324-331, 2005.

COUTO, M. A.; SANTOS, J. B. dos; FERREIRA J. L. Melhoramento do feijoeiro comum com grão tipo carioca visando resistência à antracnose e à mancha angular. Ciência e Agrotecnologia, Lavras, v. 32, n. 5 p. 16431648, set./out., 2008.

CRUZ, C.D.; CARNEIRO, P.C.S. Modelos biométricos aplicados ao melhoramento genético. Viçosa, MG: UFV, 2003. v.2, 585p.

FEHR, W.R. Principles of cultivar development. New York: MacMillan, 1987. 536p.

ISHIKAWA, F.H.; SILVA, K.J.D.; SOUZA, E.A.; DAVIDE, L.M.C.; FREIRE, C.N.S. Levantamento de raças de Colletotrichum lindemuthianum de regiões produtoras de feijão. In: CONGRESSO NACIONAL DE PESQUISA DE FEIJÃO, 7., 2005, Goiânia. Anais... Goiânia, 2005.

KNAPP, S.J.; STOUP, W.W.; ROSS, W.M. Exact intervals for heritability on a progeny mean basis. Crop Science, Madison, v.25, n.1, p.192-194, Jan./Feb. 1985.
MARQUES JÚNIOR, O.G. Eficiência com experimentos com a cultura do feijão. 1997. 80p. Tese (Doutorado)-Universidade Federal de Lavras, Lavras, 1997.

MICHELMORE, R. Molecular approaches to manipulation of disease resistance genes. Annual Review Phytopathology, Palo Alto, v.33, p.393-427, 1995.

PARRELLA, N.N.S.D.; SANTOS, J.B. dos; PARRELLA, R.A. Seleção de famílias de feijão com resistência à antracnose, produtividade e tipo de grãos carioca. Ciência e Agrotecnologia, Lavras, v.32, p.1503-1509, 2008.

PEREIRA, H.S.; SANTOS, J.B.; ABREU, A.F.B. Linhagens de feijoeiro com resistência à antracnose selecionadas quanto a características agronômicas. Pesquisa Agropecuária Brasileira, Brasília, v.39, n.3, p.209-215, mar. 2004.

PIMENTEL GOMES, F. Curso de estatística experimental. 6.ed. Piracicaba: Nobel, 1976. 427p.

RAMALHO, M.A.P.; SANTOS, J.B.; ZIMMERMANN, M J.O. Genética quantitativa em plantas autógamas: aplicação ao melhoramento do feijoeiro. Goiânia: UFG, 1993. 271p.

SARTORATO, A.; RAVA, C.A.; RIOS, G.P. Doenças fúngicas e bacterianas da parte aérea. In: ARAÚJO, R.S.; RAVA, C.A.; STONE, L.F.; ZIMMERMANN, M.J.O. (Eds.). Cultura do feijoeiro comum no Brasil. Piracicaba: Potafos, 1996. p.669-700.

SCOTT, A.J.; KNOTT, M.A. A cluster analysis method for grouping means in the analysis of variance. Biometrics, Raleigh, v.30, n.3, p.507-512, Sept. 1974.

SCHOONHOVEN, A. van; PASTOR-CORRALES, M.A. Standard system for evaluation of bean germoplasm. Cali: CIAT, 1987. 54p.

SILVA, K.J.D. Distribuição e caracterização de isolados de Colletotrichum lindemuthianum no Brasil. 2004. 86p. Dissertação (Mestrado)-Universidade Federal de Lavras, Lavras, 2004. 
SILVA, M.G.M.; SANTOS, J.B.; ABREU, A.F.B. Seleção de famílias de feijoeiro com resistência a antracnose e mancha angular. Pesquisa Agropecuária Brasileira, Brasília, v.41, n.10, p.1499-1506, 2006.

YOUNG, R.A.; KELLY, J.D. RAPD markers linked to three major anthracnose resistance genes in common bean. Crop Science, Madison, v.37, n.3, p.940-946, May/June 1997.

YOUNG, R.A.; MELOTTO, M.; NODARI, R.O.; KELLY, J.D. Marker-assisted dissection of the oligogenic anthracnose resistance in the common bean cultivar "G2333". Theorical Applied Genetics, Berlin, v.96, n.1, p.94-97, Jan. 1998. 